Extended abstract.

\title{
A web survey to evaluate the thermal stress among healthcare workers during the COVID-19 pandemic in Italy.
}

\author{
Alessandro Messeri 1,2, Michela Bonafede ${ }^{3}$, Emma Pietrafesa ${ }^{3}$, Iole Pinto ${ }^{4}$, Francesca de'Donato ${ }^{5}$, Alfonso Crisci ${ }^{2}$, \\ Jason Kai Wei Lee ${ }^{6}$, Alessandro Marinaccio ${ }^{3}$, Miriam Levi ${ }^{7}$, Marco Morabito 1,2 and on behalf of the WORKLI- \\ MATE Collaborative Group ${ }^{8}$.
}

Publisher's Note: MDPI stays neutral with regard to jurisdictional claims in published maps and institutional affiliations.

\section{(c) (i)}

Copyright: (c) 2021 by the authors. Submitted for possible open access publication under the terms and conditions of the Creative Commons Attribution (CC BY) license (http://creativecommons.org/licenses/by/4.0/).
1 Centre of Bioclimatology - University of Florence (UNIFI), Florence, Italy;

2 Institute of Bioeconomy - National Research Council (IBE-CNR), Florence, Italy;

3 Occupational and Environmental Medicine, Epidemiology and Hygiene Department, Italian Workers' Compensation Authority (INAIL), Rome, Italy;

4 Physical Agents Sector, Regional Public Health Laboratory, 53100 Siena, Italy;

5 Department of Epidemiology Lazio Regional Health Service, ASL ROMA 1, Rome, Italy;

6 Human Potential Translational Research Programme, Yong Loo Lin School of Medicine, National University of Singapore, Singapore 117593, Singapore;

7 Azienda USL Toscana Centro - UFC Epidemiologia-UFS CeRIMP del Dipartimento di Prevenzione, Firenze

8 Membership of the WORKLIMATE Collaborative Group is provided in the Acknowledgments.

* Correspondence: alessandro.messeri@unifi.it; Tel.: +39 055/5226041

\begin{abstract}
COVID 19 is a major planetary emergency and intense workloads and the potential heat stress create critical conditions for healthcare workers. A web survey was carried out in Italy during summer 2020 as part of WORKLIMATE project with the aim of assessing the interaction between Personal Protective Equipment (PPE) and heat stress in healthcare workers. Preliminary results on 191 questionnaires show an increase of heat stress perception in the areas covered by PPE determining symptoms such as thirst, sweating and general distress. This information could be useful to allow preventive measure to safeguard health and productivity of these workers.
\end{abstract}

Keywords: occupational health and safety; adaptation strategy; PPE; heat stress; global warming

\section{Introduction}

Since the beginning of 2020, humanity has been facing the most severe pandemic since the "Spanish flu" pandemic back in 1918. According to the World Health Organization (WHO), from January 1 to November 24, 2020, there were 58,712,326 COVID-19 confirmed cases and 1,388,528 deaths worldwide (https://covid19. who.int/). From the occupational point of view, healthcare workers have recorded an exponential increase in working hours [1] with intense workloads and potential heat stress. This was particularly true during the warm season, despite healthcare workers carried out most of their duties in air-conditioned environments. In addition, thermal discomfort is aggravated by the use of Personal Protective Equipment (PPE), which is necessary to reduce the risk of COVID19 disease transmission [2]. These potential adverse conditions can cause important effects on workers' health and productivity, adding further stress to healthcare systems already under great pressure due to the COVID-19 emergency [3]. Some studies based on surveys to assess the heat stress generated by COVID-19-PPE in the healthcare working sector have already been published internationally [3,4,5]. The main aim of this study was to evaluate the environmental thermal stress perceived by healthcare workers engaged in different activities in order to develop strategies to mitigate the effects of heat conditions, such as the development of a personalized heat-health warning system specific for occupational sectors. 


\section{Materials and methods}

A web survey was carried out in Italy within the WORKLIMATE project ("Impact of environmental thermal stress on workers' health and productivity: intervention strategies and development of an integrated heat and epidemiological warning system for various occupational sectors"), in order to evaluate the heat stress perceived by healthcare workers during the COVID-19 pandemic. A self-administered questionnaire, accompanied by an informed consent form, was completed by participants online (https://forms.gle/rBbJixexAaBD6m3h9). Participation was voluntary and anonymous. The survey was an adapted version of the original one developed by Lee et al. [3] that was used to assess the knowledge, attitudes, and practices of healthcare workers in India and Singapore regarding PPE usage and heat stress when performing treatment and care activities. Data were collected, stored and analyzed according to the Regulation on the protection of natural persons with regard to the processing of personal data (EU Regulation 2016/679 - General Data Protection Regulation - GDPR - application from 25 May 2018) and it was approved by the Italian National Research Council Ethics Committee (protocol N. $0009389 / 2020$ of February 6 of 2020).

\section{Results}

A total of 191 workers participated in the survey, 132 women (69.1\%) and 59 men $(30,9 \%)$. About 56\% were based in northern Italy (Table 1).

Table 1. Sample characteristics and preliminary results of the questionnaire submitted to healthcare workers.

\begin{tabular}{|c|c|c|c|}
\hline \multicolumn{2}{|c|}{ Healthcare workers } & $\mathbf{N}$. & $\%$ \\
\hline \multirow{2}{*}{ Region } & Northern & 108 & 56 \\
\hline & Central and Southern & 83 & 44 \\
\hline \multirow{2}{*}{ Gender } & Male & 59 & 31 \\
\hline & Female & 132 & 69 \\
\hline \multirow{13}{*}{ Kind of work } & General practitioner & 4 & 2 \\
\hline & Hospital doctor & 73 & 38 \\
\hline & Dentist/Orthodontist & 5 & 3 \\
\hline & Nurse/Pediatric Nurse & 64 & 33 \\
\hline & Unlicensed assistive personnel & 2 & 1 \\
\hline & Occupational therapist & 2 & 1 \\
\hline & Physiotherapist & 5 & 3 \\
\hline & Dental hygienist & 2 & 1 \\
\hline & Technician of medical radiology & 2 & 1 \\
\hline & Medical/biomedical laboratory technician & 1 & 1 \\
\hline & Healthcare assistant & 2 & 1 \\
\hline & Technician for prevention in the workplace & 4 & 2 \\
\hline & Other & 25 & 13 \\
\hline \multirow{5}{*}{ Work effort } & At rest & 2 & 1 \\
\hline & Lightweight & 13 & 7 \\
\hline & Moderate & 65 & 34 \\
\hline & High & 82 & 43 \\
\hline & Very high & 29 & 15 \\
\hline \multirow{7}{*}{ Thermal environment } & Very cold & 6 & 3 \\
\hline & Cold & 11 & 6 \\
\hline & Slightly cold & 20 & 10 \\
\hline & Neutral & 40 & 21 \\
\hline & Slightly hot & 33 & 17 \\
\hline & Hot & 53 & 28 \\
\hline & Very hot & 28 & 15 \\
\hline Dedicated rest area in the workplace & & 88 & 46 \\
\hline Heat stress in the areas covered by PPE & & 150 & 78 \\
\hline \multirow{5}{*}{$\begin{array}{l}\text { Symptoms generally perceived with PPE (mul- } \\
\text { tiple choice) }\end{array}$} & Thirst & 11 & 58 \\
\hline & Excessive sweating & 135 & 71 \\
\hline & Fatigue & 88 & 46 \\
\hline & Headache & 82 & 43 \\
\hline & Difficulty concentrating & 56 & 29 \\
\hline
\end{tabular}




\begin{tabular}{lccc} 
& Skin reaction & 51 & 27 \\
& General discomfort & 99 & 52 \\
\hline Productivity loss perception (heat stress) & & 155 & 81 \\
\hline
\end{tabular}

N. Frequency; \% Percentage.

The collected sample is quite heterogeneous and comprises many types of professions in the health sector even if the most represented are hospital physicians (38.2\%) and nurses, including pediatric nurses (33.5\%). With regards to work commitment and therefore work effort, about $43 \%$ declared an intense effort and $15 \%$ very intense; $34 \%$ moderate and only $7 \%$ lightweight. About $60 \%$ of workers declared they perceived hot and $14.7 \%$ even very hot conditions, despite the working environment being indoor and air-conditioned, probably because most of workers declared to be involved in intense work effort.

Figure 1 shows the prevalent thermal sensation declared by workers for each body district.

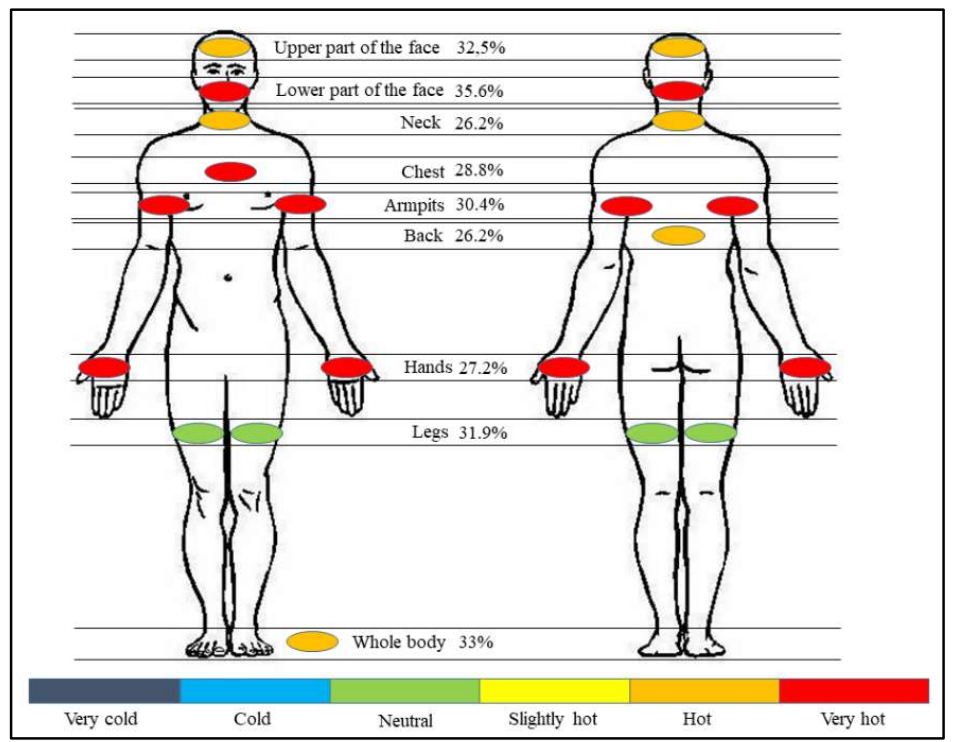

Figure 1. Prevalent thermal sensations declared by healthcare workers for each parts of the body covered by PPE during working time.

The body parts represented by prevalent "hot" or "very hot" conditions were the hands $(27.2 \%)$, the lower part of the face (35.6), armpits (30.4) and chest (28.8\%). A general whole body thermal sensation characterized by prevalent "hot" conditions (33\%) was observed. In addition, $78 \%$ of respondents reported to perceive heat stress in areas of the body covered by PPE which, according to the workers' opinions, causes thirst (58.1\%), excessive sweating $(70.7 \%)$, fatigue $(46.1 \%)$, headache $(42.9 \%)$ and general discomfort $(51.8 \%)$. Less than half of respondents ( $46 \%$ of workers) reported that there is a dedicated refreshment area in their workplace and, according to $81 \%$ of workers, heat stress conditions in the workplace lead to a productivity loss.

\section{Discussion and Conclusion}

Results showed that, despite the workplaces in which the healthcare workers carry out their activities were generally air-conditioned, they often declared heat stress perception, particularly in the parts of the body that were covered by PPE. These preliminary results confirm what Tabah et al (2020) recently found in an international web-based survey conducted in Europe, Australia and New Zeeland countries \cities to elicit health care workers reports surrounding PPE related to the COVID-19 pandemic. In addition, workers declared a productivity loss linked to heat stress, as also confirmed in recent international surveys. In particular, Davey et al (2020) highlighted how 76.2\% of the workers interviewed declared a loss of productivity linked to the stress conditions caused by PPE. 
In addition, Lee et al (2020) confirmed that a majority of healthcare workers reported that heat stress was able to adversely influence their productivity, judgment, and emotions. Results for the survey will be reported in further detail in the special issue " $S$ elected Papers from the 3rd International Electronic Conference on Environmental Research and Public Health - Public Health Issues in the Context of the COVID-19 Pandemic", especially considering some individual characteristics (age, gender, physiological characteristics, tasks and behavior) which probably play an important role in the thermal perception of workers, highlighting significant differences among different categories of workers. The survey will also be replicated during next summer and an improvement in the administration strategy will also be evaluated, move from the self-administration method to the administration method assisted by a competent doctor or prevention and protection service staff, to avoid the current bias due to the self-administration.

These results may be particularly useful to plan and develop the appropriate interventions to manage the heat stress and protect the healthcare workers' health and improve their productivity, while keeping the measures to contrast COVID-19 as well as other possible occupational hazards a priority.

Author Contributions: Conceptualization, Marco Morabito and Alessandro Messeri; methodology, Michela Bonafede.; software, Pietrafesa Emma.; validation, Alfonso Crisci., Francesca de Donato and Miriam Levi.; formal analysis, Michela Bonafede; investigation, Alfonso Crisci; resources, Alessandro Marinaccio.; data curation, Jason Kai Wei Lee; writing-original draft preparation, Alessandro Messeri.; writing - review and editing, all authors.; visualization, Iole Pinto; supervision, Alessandro Marinaccio.; project administration, Marco Morabito.; funding acquisition, Marco Morabito. All authors have read and agreed to the published version of the manuscript.

Funding: This research was funded by the Italian Institute for Insurance against Accidents at Work (INAIL) in the field of BRIC 2019 call (WORKLIMATE Project)

Conflicts of Interest: The authors declare no conflict of interest. The funders had no role in the design of the study; in the collection, analyses, or interpretation of data; in the writing of the manuscript, or in the decision to publish the results.

\section{References}

1. Kramer A.; Kramer K.Z. The potential impact of the Covid-19 pandemic on occupational status, work from home, and occupational mobility. Journal of Vocational Behavior 2020, 119, 103442.

2. Morabito, M.; Messeri A.; Crisci A.; Pratali L.; Bonafede M.; Marinaccio A.; on behalf of the WORKLIMATE Collaborative Group. Heat warning and public and workers' health at the time of COVID-19 pandemic. Science of the Total Environment 2020, 10, (p.738). https://doi.org/10.1016/j.scitotenv.2020.140347

3. Lee J.; Venugopal V.; Latha PK.; Ahadad SB.; Wei Leow C..;, De Goh N.Y.; Tan E.; Kjellstrom T.; Morabito M.; Wei Lee J.K. Heat Stress and Thermal Perception amongst Healthcare Workers during the COVID-19 Pandemic in India and Singapore. International Journal of Environmental Research and Public Health 2020, 17, 8100. doi:10.3390/ijerph17218100

4. Davey S..;, Lee B.J.; Robbins T.; Randeva H.; Thake D. Heat Stress PPE during COVID-19: Impact on health care workers' performance, safety and well-being in NHS settings. MedRxiv preprint 2020 https://doi.org/10.1101/2020.09.22.20198820

5. Tabah A.; Ramanan M.; Laupland K.B.; Buetti N.; Cortegiani A.; Mellinghoff J.; Morris A.C.; Comporota L.; Zappella N.; Elhadi M.; Povoa P.; Amrein K.; Vidal G.; Derde L.; Bassetti M.; Francois G.; Kai N.S.K.; De Waele J.J.; the PPE-SAFE contributors. Personal protective equipment and intensive care unit healthcareworker safety in the COVID-19 era (PPE-SAFE): An international survey Journal of Critical Care 2020, 59, (pp70-75). https://doi.org/10.1016/j.jcrc.2020.06.005 